\title{
Sliding Mode Control Based on Internal Model for a Non-minimum phase Buck and Boost Converter
}

\section{(Control por Modo Deslizante Basado en Modelo Interno para un Convertidor Buck-Boost de Fase no Mínima)}

\author{
Byron Cajamarca, ${ }^{1}$ Oscar Camacho, ${ }^{1}$ Danilo Chávez, ${ }^{1}$ Paulo Leica, ${ }^{1}$ Marcelo Pozo ${ }^{1}$
}

\begin{abstract}
This work presents the application of different schemes to control a non-minimum phase Buck-Boost converter. Three control schemes are used. The first controller presented is a PI controller, the second one is Sliding Mode Control and the third one is a combination of two control schemes, Internal Model Control and Sliding Mode Control. The controllers are designed from a Right-Half Plane Zero (RHPZ) reduced order model. The RHPZ model is converted, using Taylor approximation, in a First Order Plus Dead Time (FOPDT) model and after that, the controllers are obtained. The performance of the SMC-IMC is compared against to a PI controller and a SMC. The simulation results show that SMC-IMC improves the converter response, reducing the chattering and presenting better robustness for load changes
\end{abstract}

Keywords

Buck-Boost; non-minimum phase system; internal model control; sliding mode control; chattering.

\begin{abstract}
Resumen
Este trabajo presenta la aplicación de diferentes esquemas para controlar un convertidor Buck-Boost de fase no mínima. Se utilizan tres esquemas de control. El primer controlador es un controlador PI, el segundo es un controlador por Modos Deslizantes y el tercero es una combinación de dos esquemas de control, por Modelo Interno y por Modos Deslizantes. Los controladores están diseñados a partir de un modelo de orden reducido con un Cero en el Semiplano Derecho (CSPD). El modelo CSPD se convierte, utilizando la aproximación de Taylor, en un modelo de Primer Orden con Tiempo Muerto (POMTM) y luego se obtienen los controladores. El rendimiento del SMC-IMC se compara con un controlador PI y un SMC. Los resultados de la simulación muestran que SMC-IMC mejora la respuesta del convertidor, reduciendo el parloteo y presentando una mayor robustez para los cambios de carga.
\end{abstract}

\section{Palabras clave}

Buck-Boost; sistema de fase no mínima; control por modelo interno; control por modo deslizante; chattering.

\section{Introduction}

The Buck-Boost Converter (B-BC) is a DC / DC topology of power converters. DC-DC power converters are widely used in various applications such as in electrical power generation through photovoltaic systems, in DC energy storage systems, in DC power regulation systems, in photovoltaic power generation systems, aviation industry, aerospace technology and other fields (Rozanov, Ryvkin, Chavligin and Voronin, 2016).

A B-BC can be considered as a non-minimum phase system, which is characterized by the presence of a right-half plane (RHP) zero in the transfer function of system, when it receives the capacitance voltage as its output for feedback control. The ZRHP produces that the system operates in opposite direction during the initial transient response, affecting the dynamic response of the system. The non-minimum phase response of a Buck-Boost converter which

1 Departamento de Automatización y Control Industrial - Escuela Politécnica Nacional, Quito - Ecuador (\{byron.cajamarca, oscar.camacho, danilo.chavez, paulo.leica, marcelo.pozo\} @epn.edu.ec). 
works in Continuous Conduction Mode (CCM) is related to its inductance, load and duty ratio (Forouzesh M. et al 2017). Huang and Liu, (2016) present an analysis for non-minimum DC/DC converter. Internal model Control (IMC) has been used to eliminate problems originated by nonminimum phase behavior. Tarakanath, Pathwardan and Agarwal, (2014) present a study using IMC structure for Boost Converters. Other control structure is the sliding mode control (SMC). The design of SMC is attractive because it can deal with non-linear systems and exhibits robustness against modeling error and disturbances (Camacho and Lacruz, 2014). However, SMC can present a problem when it is used in the Buck-Boost causing chattering in the control action that is not ideal for the actuator, thus a hybrid approach (SMC-IMC) (Camacho, Smith and Moreno, 2003) can help in this sense.

This article shows the application of different control schemes to control a non-minimum phase Buck-Boost converter. Three control schemes are used. The first controller presented is a PI controller, the second one is Sliding Mode Control and the third one is a combination of two control schemes, Internal Model Control and Sliding Mode Control. The controllers are designed from a Right-Half Plane Zero (RHPZ) reduced order model. The RHPZ model is converted, using Taylor approximation, in a First Order Plus Dead Time (FOPDT) model and after that, the controllers are obtained. The performance of the SMC-IMC is compared against to a PI controller and a SMC. The simulation results show that SMC-IMC improves the converter response, reducing the chattering and presenting better robustness for load changes.

\section{Fundamentals}

\subsection{Converter Description}

The topology of Buck-Boost converter is shown in Figure 1. This converter is a cascade connection of two basic converters: Buck converter and Boost converter. The notation used are: $L$ is the inductance, $C$ is the capacitance, $R$ is the Resistance, $V_{i n}$ is the input voltage, $V_{o}$ is the voltage in the load, $V_{c}$ is the voltage in the capacitor, $i_{c}$ is the current in the capacitor, $V_{L}$ is the voltage in the inductor.

Figure 1. Buck-Boost Converter DC/DC topology

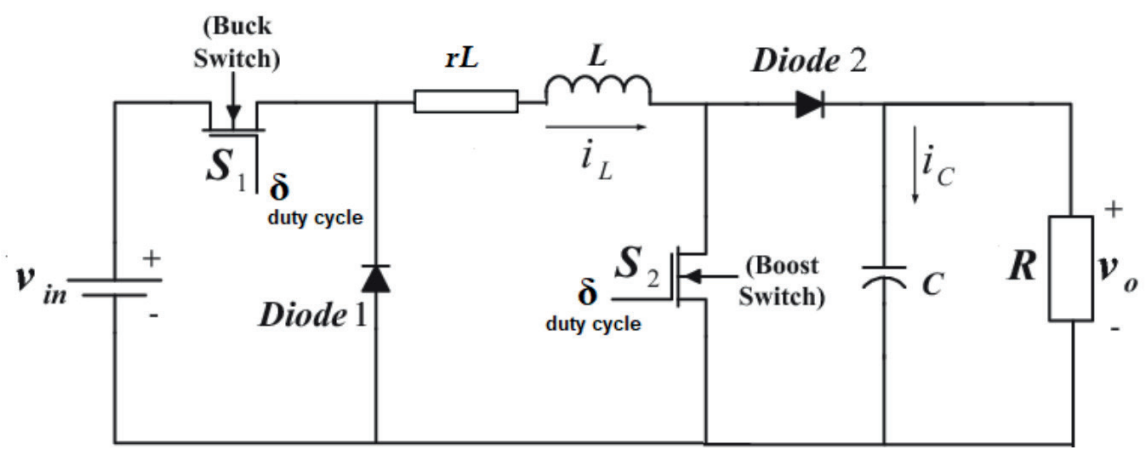

Switches S1 and S2 work simultaneously, i.e. they work with the same action control; modifying the duty cycle $(\delta)$ from 0 to 0.5 the converter works as Buck mode and from 0.5 to 1 it works as Boost mode. The variable to be controlled in the $\mathrm{DC} / \mathrm{DC}$ converter is the output voltage 
in the load, the manipulated va56riable will be the duty cycle $(\delta)$. The parameters used to analyze the Buck-Boost converter are shown in Table 1.

Table 1. Parameters of Buck-Boost Converter

\begin{tabular}{|c|c|c|c|}
\hline Parameters & Value & Parameters & Value \\
\hline$V_{\text {in }}$ & $12[\mathrm{~V}]$ & $L$ & $60[\mathrm{mH}]$ \\
\hline$V_{0}$ & $24[\mathrm{~V}]$ & $r_{L}$ & {$[\mathrm{~m} \Omega]$} \\
\hline$R$ & $10[\Omega]$ & $i_{L}$ & $7.69[\mathrm{~A}]$ \\
\hline$C$ & $50[\mathrm{uF}]$ & $(\delta)$ & 0.688 \\
\hline
\end{tabular}

\subsection{Modeling of converter}

For modeling Buck-Boost converter two important conditions are considered. First, the converter works in continuous conduction mode and second is that the power semiconductor device work as an ideal switch, i.e. the semiconductor doesn't dissipate power. Therefore, the input power is the same that the output power in the converter. The mathematical analysis of converter is carried out considering the switches S1, S2 in two positions (On/Off). The following equations are obtained from the Buck-Boost analysis scheme (Figure 2).

Figure 2. Buck-Boost converter analysis scheme

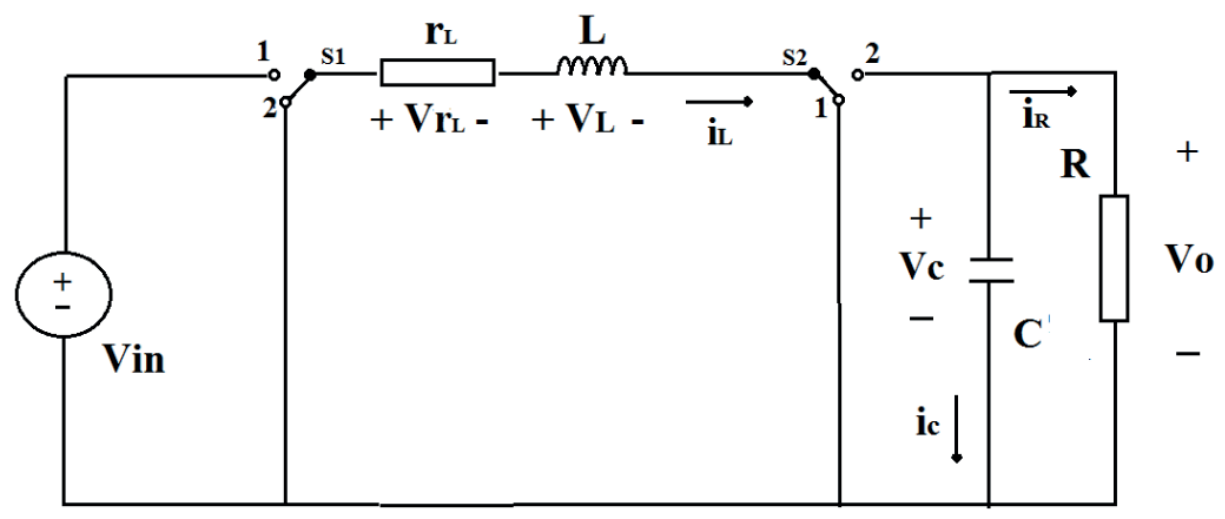

For the first case of analysis, switches S1 and S2 are in position 1, the converter response is described by Equation 1 and Equation 2.

$$
\begin{gathered}
V_{L}=V_{\text {in }}-i_{L} r_{L} \\
i_{C}=-\frac{V_{o}}{R}
\end{gathered}
$$

For the second case of analysis, switches $S 1$ and $S 2$ are in position 2, the converter response is described by Equation 3 and Equation 4:

$$
V_{L}=-\left(V_{C}+i_{L} r_{L}\right)
$$




$$
i_{C}=i_{L}-\frac{V_{o}}{R}
$$

Combining Equation 1, Equation 2, Equation 3 and Equation 4, is obtained the dynamic behavior of Buck-Boost converter described by Equation 5 and Equation 6.

$$
\begin{gathered}
\frac{d i_{L}}{d t}=\frac{V_{L}}{L}=\frac{\left(V_{\text {in }}-i_{L} r_{L}\right) \delta}{L}-\frac{\left(V_{o}+i_{L} r_{L}\right)(1-\delta)}{L} \\
\frac{d V_{C}}{d t}=\frac{i_{C}}{C}=\frac{i_{L}(1-\delta)}{C}-\frac{V_{o}}{R C}
\end{gathered}
$$

Analyzing Equation 5 in steady state $\frac{d i_{L}}{d t}=0$ is obtained Equation 7.

$$
V_{C}=V_{o}=\frac{V_{i n} \delta-i_{L} r_{L}}{(1-\delta)}
$$

\subsection{Linear Model Approximation}

Buck-Boost converter is approximated to a linear model to facilitate the design of controllers. To obtain a linear approximation of the system, a reaction curve is applied to the converter because it has a first order dynamic behavior. The method used to approximate the model is the "First Order Plus Dead Time" (FOPDT) proposed by Smith and Corripio, 1997. Equation 8 represents the linear approximation of system. To use the approaches proposed by Camacho, Rojas and García, (1999) and Camacho, Smith and Moreno (2003), let us $\zeta_{1}=t_{o}$.

$$
G(s)=\frac{K\left(1-\zeta_{1} s\right)}{(\zeta s+1)} \approx \frac{K e^{-\zeta_{1} s}}{(\zeta s+1)}
$$

\subsection{Control Schemes}

\section{Internal Model Control (IMC)}

IMC is a control scheme used in systems with non-minimum phase dynamic. The presence of delay and RHP zero in the system can originate non-invertible controllers which are not possible to implement. Therefore, is necessary to eliminate delay and RHP zero of the control loop. IMC eliminates the non-invertible part of non-minimum phase systems of the control loop to get an implementable controller. The transfer function of system $G m(s)$ is separated in two parts to delete the control problems. The first part $\mathrm{Gm}^{-}(s)$ contains the invertible part of model and the second part $\mathrm{Gm}^{+}(s)$ contains the non-invertible part of model. Below is shown the separation of model in Equation 9. 


$$
G m(s)=G m^{+}(s) \cdot G m^{-}(s)
$$

For the design of IMC, the FOPDT approach (Equation 8) is used; it presents a delay in the model of system, and generates a non-invertible controller. According to what was mentioned in Equation 9, it's necessary to separate the non-invertible part of the model. The delay is separated from the transfer function of the system FOPDT and origins a transfer function as shown in Equation 10. The new transfer function of system without delay is shown in Equation 11. The IMC scheme is observed in Figure 3.

$$
\begin{gathered}
G m^{+}(s)=e^{-t_{o} s} \\
G m^{-}(s)=\frac{K}{(\zeta s+1)}
\end{gathered}
$$

Figure 3. Internal Model Control Scheme

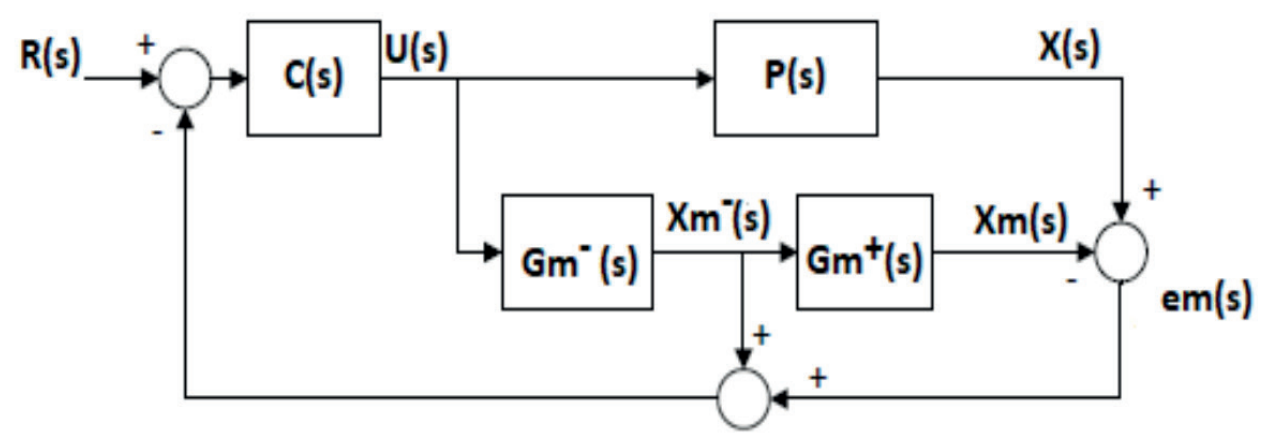

Where:

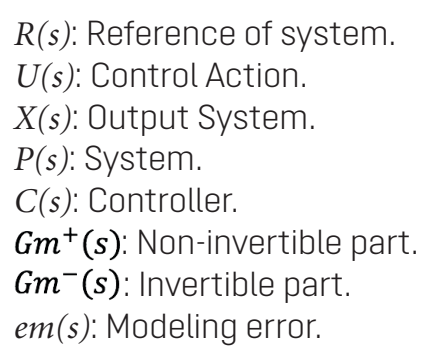

\section{Sliding Mode Control (SMC)}

The idea of SMC is to define a surface with which the system can slide to its desired final value (Figure 4). The first step to design this controller is choose the sliding surface $S(t)$ to define a global behavior for the system. The SMC control action $U(t)$ consists of two additive parts (Equation 12). The first part is called discontinuous action $U_{D}(t)$ and it helps the system to reach the sliding surface. The second part is called continuous action $U c(t)$ and it helps the system to stay on the sliding surface (Dominguez et al, 2016). 


$$
U(t)=U_{D}(t)+U_{C}(t)
$$

Figure 4. Sliding and Reaching Mode

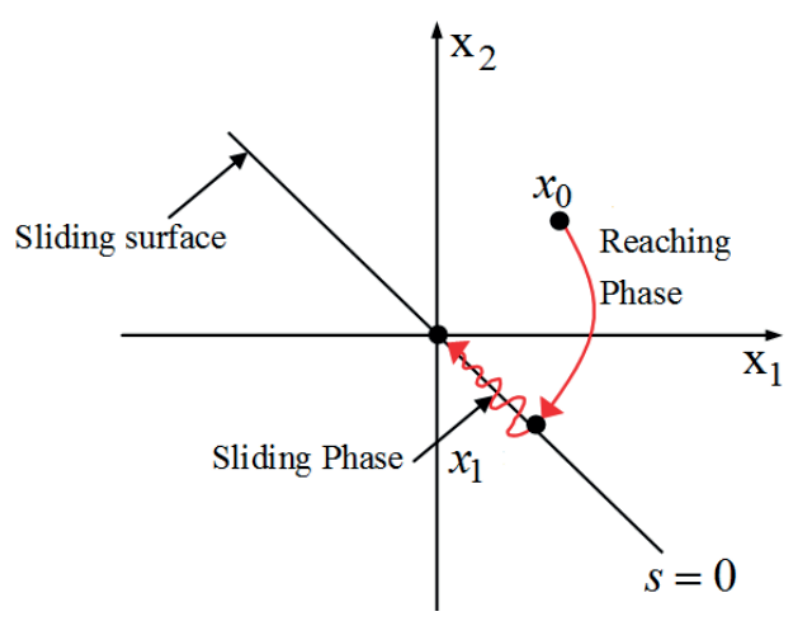

Sometimes, one problem that SMC presents is the chattering, this phenomenon consists in high-frequency oscillations around the value desired in the output of system. It happens when the discontinuous action reaches the sliding surface abruptly. Also, it causes that the control action damage to the actuator and appear unwanted dynamics in the system. Discontinuous control action $U_{D}(t)$ is based on Equation 13, the sign function is the discontinuous element.

$$
U_{D}(t)=K_{D} \operatorname{sign}(S(t))
$$

\section{Design of Controllers}

\subsection{Pl Controller}

For tuning the PI controller (Equation 14), the FOPDT model of system (Equation 8) was used. The tuning method of Dahlin (Smith and Corripio, 1997) was considered.

$$
P I(s)=K c\left(1+\frac{1}{T i s}\right)
$$

Where:

$$
K c=0.0085 ; T i=0.0689
$$

\subsection{SMC Controller}

The method to design this controller was proposed by Camacho, Rojas and Garcia, (1999). It is a simple way of designing a SMC controller, and it can be generalized as a method of design for 
several processes. This last feature is the main difference with the original SMC (Tahri F., Tahri A. and Flazi, 2014), because the original procedure is based on a specific mathematic model of system and the design is exclusive for that system. For the design of SMC controller is used a linear approximation of the system FOPDT (Equation 8).

The design of SMC controller is shown in the work of Camacho, Garcia and Rojas, (1999). The sliding surface chosen in this work is presented in Equation 15.

$$
S(t)=\frac{d e(t)}{d t}+\lambda_{1} e(t)+\int \lambda_{0} e(t) d t
$$

The controller equation designed by Camacho is presented in Equation 16.

$$
U(t)=\frac{\zeta t_{o}}{K}\left[\frac{Y(t)}{\zeta t_{o}}+\lambda_{o} e(t)\right]+K_{D} \frac{S(t)}{|S(t)|+\rho}
$$

The parameters for $S(t)$ and $U(t)$ based on equations of Camacho are:

$$
\lambda_{1}=40.1, \quad \lambda_{o}=209.1, K_{D}=0.024, \quad \rho=30
$$

\subsection{SMC-IMC Controller}

For the design of SMC-IMC controller, FOPDT approach model (Equation 8) is used. One problem of FOPDT approximation is the delay, to solve this problem the delay is eliminated of the control loop through the internal model structure. Therefore, the model of system without delay (Equation 11) is used to design this controller. SMC is added to the internal model scheme to improve the robustness of the system (Camacho, Smith and Moreno, 2003). Figure 5 shows the structure of SMC-IMC proposed in this work.

Figure 5. Sliding Mode control base on Internal Model (SMC-IMC) scheme

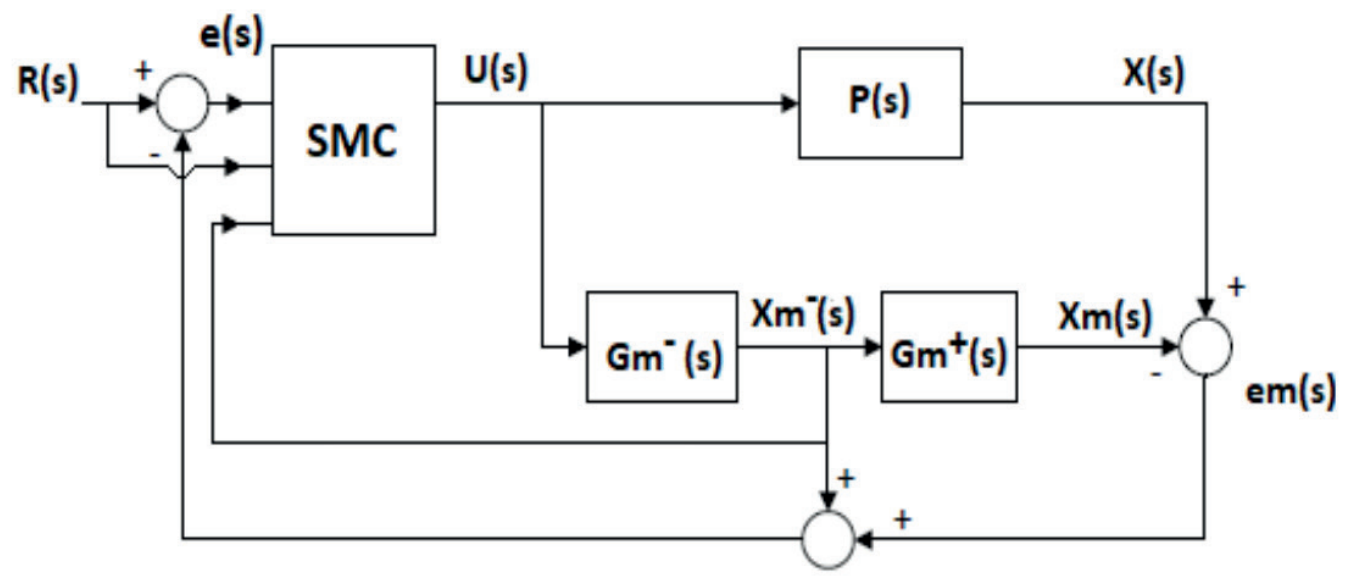

Below, the design of SMC-IMC controller is presented. First, a sliding surface is chosen to define a global behavior for the system. The sliding surface chosen is shown in Equation 17. 


$$
S(t)=e^{-}(t)+\int \lambda e(t) d t
$$

Equation 18 represents the error of system.

$$
e(t)=R(t)-X(t)
$$

Equation 19 represents the error of system considering it without delay.

$$
e^{-}(t)=R(t)-X m^{-}(t)
$$

The condition that must be met for the system to follow the reference and remain stable on the sliding surface is shown in Equation 20:

$$
\dot{\boldsymbol{s}}(\boldsymbol{t})=\mathbf{0}
$$

The continuous part $U_{c}(t)$ is designed below. The solution of the output of Equation 11 is presented in Equation 21.

$$
\frac{d X_{m}^{-}(t)}{d t}=K \frac{U(t)}{\zeta}+\frac{X_{m}{ }^{-}(t)}{\zeta}
$$

Considering Equation 20, the sliding surface (Equation 17) is derived.

$$
\dot{S}(t)=\frac{d e^{-}(t)}{d t}+\lambda e(t)
$$

Substituting Equation 19 into Equation 22, is obtained Equation 23:

$$
\dot{S}(t)=0=\left(\frac{d R(t)}{d t}-\frac{d X_{m}{ }^{-}(t)}{d t}\right)+\lambda e(t)
$$

Now replacing Equation 21 into Equation 23, is obtained Equation 24:

$$
U_{C}(t)=\frac{\zeta}{K}\left[\frac{X_{m}{ }^{-}(t)}{\zeta}+\lambda e(t)\right]
$$

According by Camacho, Smith and Moreno, (2003), the tuning parameters are presented by Equation 25, 26 and 27 :

$$
\begin{gathered}
\lambda \leq \frac{1}{\zeta+t_{o}}[\text { time }]^{-1} \\
K_{D}=\frac{0.8}{K}\left(\frac{\zeta}{t_{o}}\right)^{0.76} \\
\rho=0.68+0.12|K| K_{D} \lambda
\end{gathered}
$$


The discontinuous part $U_{D}(t)$ is based in Equation 13, the sign function is approximated as observed in Equation 28.

$$
U_{D}(t)=K_{D} \frac{S(t)}{|S(t)|+\rho}
$$

Adding Equation 26 and Equation 28 is obtained the control action (Equation 29).

$$
U(t)=\frac{\zeta}{K}\left[\frac{X_{m}^{-}(t)}{\zeta}+\lambda e(t)\right]+K_{D} \frac{S(t)}{|S(t)|+\rho}
$$

The theory of Lyapunov is applied to analyze the stability of controller. Lyapunov's function (Equation 30) chose is the sliding surface (Equation 17). Lyapunov's condition is presented in Equation 31.

$$
\begin{gathered}
V(t)=\frac{S^{2}(t)}{2}>0 \\
\frac{d V(t)}{d t}<0
\end{gathered}
$$

Applying condition Equation 31 in Equation 30 is obtained Equation 32.

$$
\frac{d V(t)}{d t}=S(t) \dot{S}(t)<0
$$

Replacing Equation 23 into Equation 32, results Equation 33.

$$
S(t)\left[\frac{d R(t)}{d t}-\frac{d X_{m}{ }^{-}(t)}{d t}+\lambda e(t)\right]<0
$$

Replacing Equation 21 into Equation 33, is obtained Equation 34:

$$
S(t)\left[\frac{d R(t)}{d t}-\left(K \frac{U(t)}{\zeta}+\frac{X_{m}{ }^{-}(t)}{\zeta}\right)+\lambda e(t)\right]<0
$$

Replacing Equation 29 into Equation 34, results Equation 35.

$$
S(t)\left[\frac{d R(t)}{d t}-\left(\frac{K}{\zeta}\left(\frac{\zeta}{K}\left[\frac{X_{m}{ }^{-}(t)}{\zeta}+\lambda e(t)\right]+\frac{K_{D} S(t)}{|S(t)|+\rho}\right)+\frac{X_{m}{ }^{-}(t)}{\zeta}\right)+\lambda e(t)\right]<0
$$

Solving Equation 35 is obtained the stability condition presented in Equation 36.

$$
K_{D}>0
$$

The parameters of $S(t)$ and $U(t)$ were tuned according to Equation 25, 26 and 27.

$$
\lambda=4, \quad K_{D}=0.032, \rho=0.79
$$




\section{Simulation Results}

Using the parameters of Table 1 and the model FOPDT (Equation 8), is obtained the transfer function (Equation 37), it is a linear approximation of Buck-Boost converter.

$$
G(s)=\frac{106.01 e^{-0.0379 s}}{(0.0689 s+1)}
$$

As shown in Figure 6 the FOPDT approximation does not consider the inverse peak in the response of Buck-Boost converter

Figure 6. FOPDT approximation of Buck-boost converter applying a $5 \%$ variation in the input

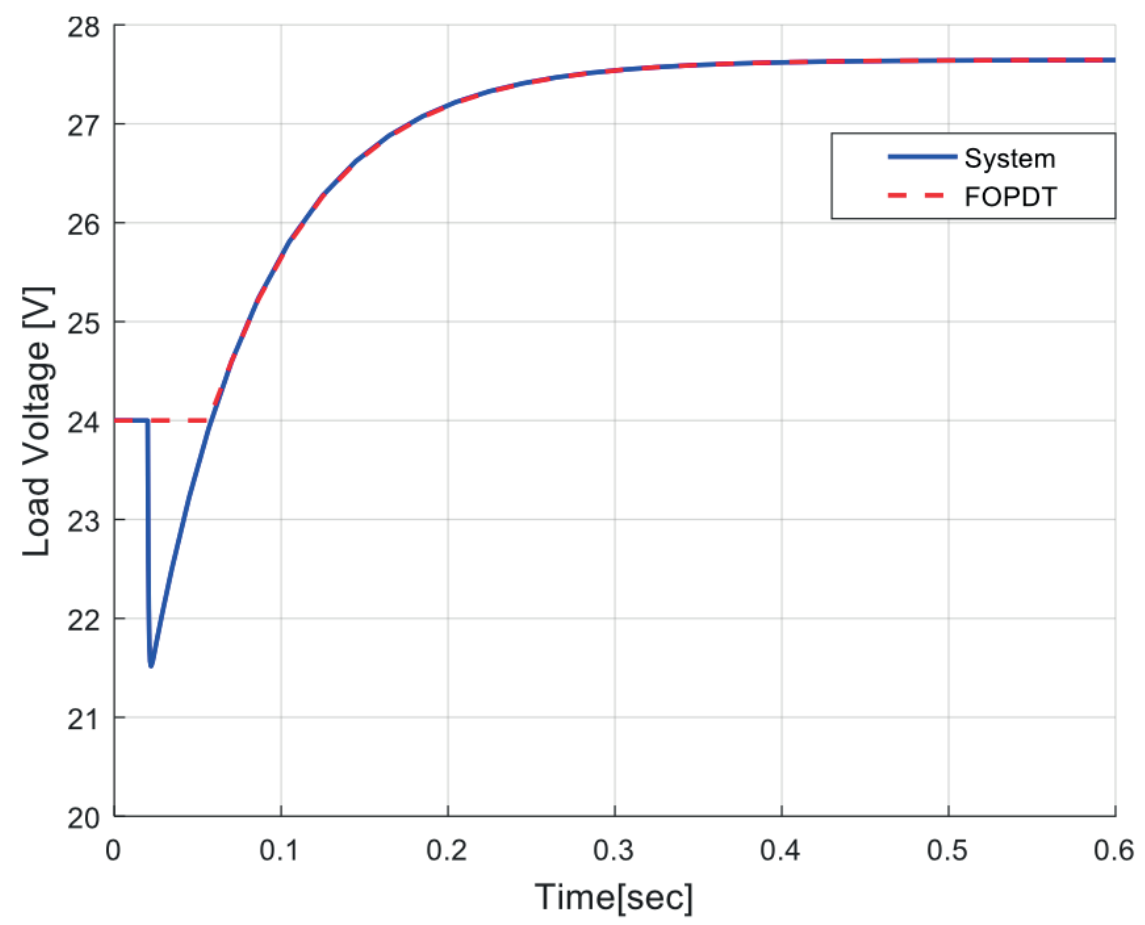

Two tests are implemented to verify the performance of the proposed controllers. First, a step reference change around the operation point is applied in the converter. In the second test, the converter works on the operation point under load disturbances. The controllers are compared through performance indicators as ISE (Integral squared error), Ts (Stand Time), MPI (Undershoot).

\subsection{Set-point step change result}

The variation of set-point is from $10 \%$ with respect of the output as shown in the Figure 7 and 8. The control action of SMC present chattering phenomenon as shown in Figure 7. Therefore, this controller is not recommendable to implement in this Buck-Boost converter. 
Figure 7. a) Response of system for a 10 \% Setpoint change using SMC controller, b) Control action

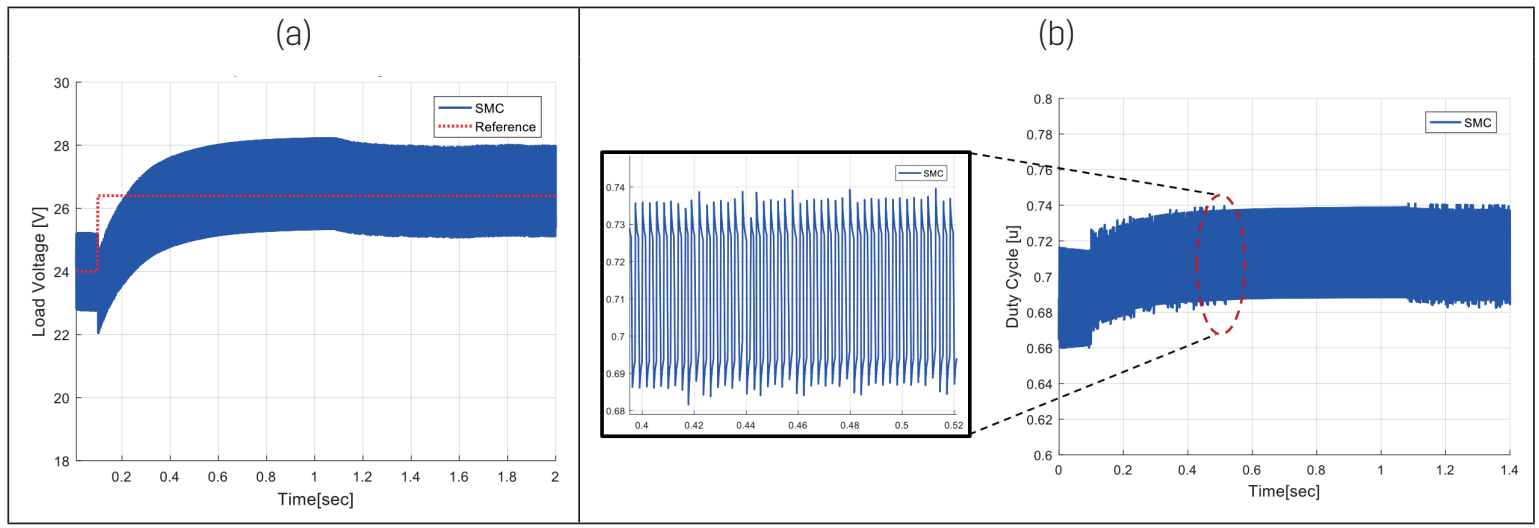

Below, there are the graphs corresponding to the simulation of the PI and SMC-IMC controller applied to the Buck-Boost converter. Table 2 shows the performance indicators to analyze the operation of the controllers.

Table 2. Controller Performance Indicators

\begin{tabular}{|l|c|c|c|}
\hline \multicolumn{1}{|c|}{ Controller } & ISE & MPI \% & Ts[sec] \\
\hline PI & 0.6672 & 16.25 & 0.325 \\
\hline SMC & 4.6 & 16.45 & 1.1 \\
\hline SMC-IMC & 0.7352 & 9.16 & 0.78 \\
\hline
\end{tabular}

Figure 8. a) Response of system for $10 \%$ setpoint step change b) Control action

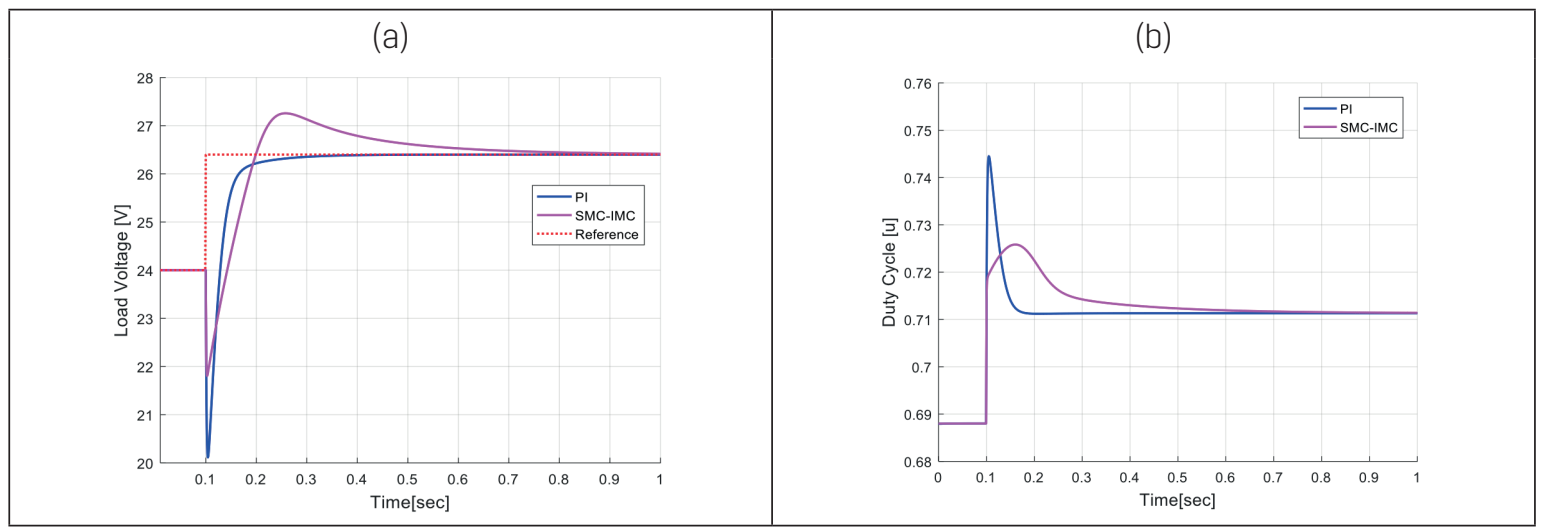

\subsection{Load Disturbances Changes}

The Load Disturbances applied to the converter are variables with the time (Figure 9). The variation of the resistive load is from $10 \%$ to $60 \%$ respect the initial load, the response of converter is shown in Figure 10. 
Figure 9. Load Disturbances

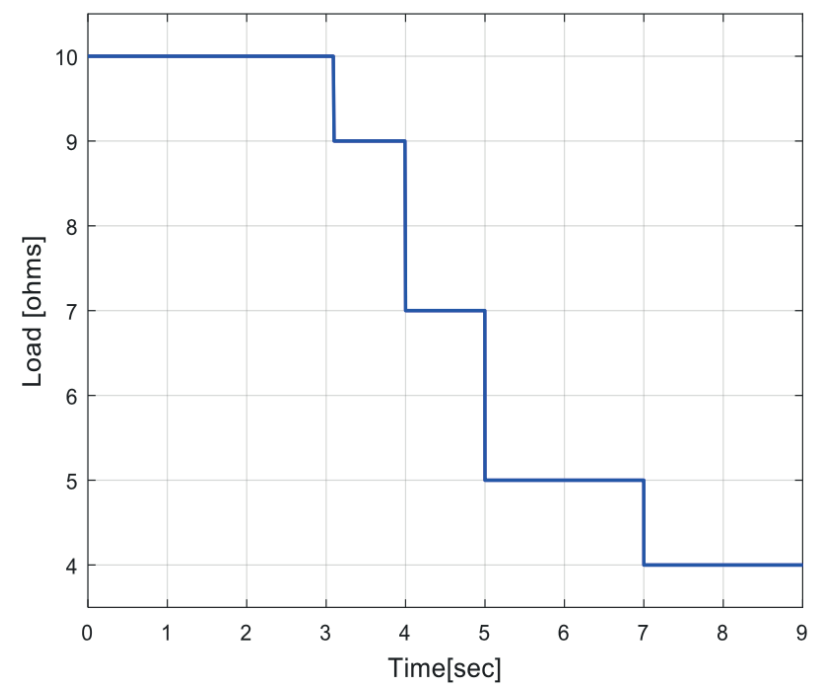

Figure 10. a) Dynamic load disturbances response b) Control Action

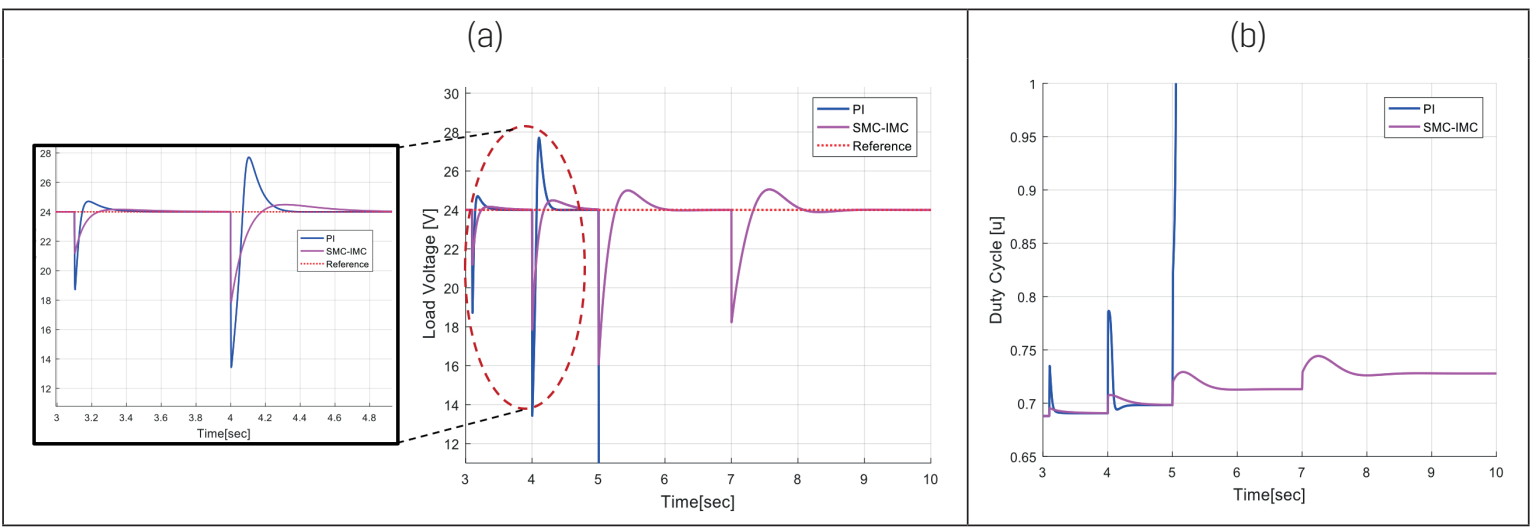

In Table 3 the parameters MPI \%, Ts were obtained to the second disturbance, ISE parameter was obtained for all disturbances. ISE parameter of PI controller is very high because the system became unstable as shown in Figure 10.b.

Table 3. Controller Performance Indicators

\begin{tabular}{|l|c|c|c|}
\hline \multicolumn{1}{|c|}{ Controller } & \multicolumn{1}{c|}{ ISE } & MPI \% & Ts[sec] \\
\hline PI & \multicolumn{1}{|c|}{2856} & 41.66 & 0.325 \\
\hline SMC-IMC & 8.8 & 25 & 0.7 \\
\hline
\end{tabular}

\section{Conclusions}

Three controllers were evaluated to a non-minimum phase DC/DC converter.

Classical methods usually have not good performance when they are used for non-minimum phase electrical systems. 
The application of SMC directly to non-minimum phase converters produce chattering to the final control element, which is not a desired condition.

The approach using SMC-IMC controller reduces the chattering phenomenon to a minimum and provides good performance and robustness for tracking and load changes.

The combination of classical control schemes plus robust methods is an alternative to continue experimenting.

\section{References}

Al-Hadithi B.M., Barragan A.J., Andujar J.M. and Jimenez A. (2016). Chattering-free variable control structure for multivariable nonlinear systems. Elsevier Science Publisher B.V, vol 39, Netherlands, 165-187.

Camacho O. and de La Cruz F. (2014). Controlador de Modos Deslizantes basado en Predictor de Smith y Modelo de Segundo Orden para Procesos con Elevado Retardo. Revista Politécnica 35 (2), 18-24.

Camacho O., Rojas R., and García W. (1999). Variable Structure Control applied to chemical processes with inverse response. ISA Transactions, 56-63.

Camacho O., Smith C. and Moreno W. (2003). Development of an internal model sliding mode controller. Industrial \& Engineering Chemistry Research 42, 568-573.

Dominguez X., Camacho O., Leica P. and Rosales A. (2016). A Fixed-Frequency Sliding-mode Control in a Cascade Scheme for the Half-Bridge Bidirectional DC-DC Converter. 2016. IEEE Ecuador Technical Chapters Meeting (ETCM). DOI: 10.1109/ETCM.2016.7750835

Forouzesh M., Siwakoti Y. P., Gorji S. A., Blaabjerg F. and Lehman B. (2017) Step-Up DC-DC Converters: A Comprehensive Review of Voltage Boosting Techniques, Topologies, and Applications. IEEE Transactions on Power Electronics 32(12):9143-9178.

Huang J., and Liu S. (2016). Analysis of Non-minimum Phase in Buck-Boost Converter. MATEC Web of conferences 55, ACPPE 2016, 1-6.

Rozanov Y., Ryvkin S., Chavligin E. and Voronin P. (2016). Powers Electronics Basics. New York, EE.UU.: Editorial CR Press, Taylor \& Francis Group. p 241-264.

Smith C. and Corripio A. (1997). Principles and Practice of Automatic Process Control. Second Edition. New York, EE.UU.: Editorial Limusa Wiley. p 314-315.

Tahri F., Tahri A. and Flazi S. (2014). Sliding mode Control for DC-DC Buck Converter. Third International Conference on Power Electronics and Electrical Drives ICPEED'14, Algeria, 1-5.

Tarakanath K., Pathwardan S. and Agarwal V. (2014). Internal Model Control of dc-dc Boost Converter Exhibit Non-Minimum Phase Behavior. IEEE PEDES 2014, 1-8. 